\title{
The Stable Connection to the Metropolitan Area of the Strait of Messina
}

\author{
Alessandro Rugolo ${ }^{1, a}$ \\ ${ }^{1}$ Mediterranea University of Reggio Calabria - PAU - Department of Heritage, Architecture, Urban \\ Planning, Via Salita Melissari - 89124, Reggio di Calabria, Italy \\ aalessandro.rugolo@unirc.it
}

Keywords: Metropolitan Area, Integration, Infrastructures.

\begin{abstract}
The contemporary model of the city is linked to the dynamics of information flows and economic and cultural influences. Consequently, the traditional administrative organization has proved inadequate favoring the definition of a new model of governance of urban areas, able to administer the complexity. This characteristic is typical of the metropolitan city, which requires a new institutional framework is equipped with tools and infrastructure suitable to govern the phenomena of mobility, economic development and transformations in the regime of synergistic and integrated. The metropolitan system the Strait of Messina need for a stable connection that ensures the conurbation of the two sides.
\end{abstract}

\section{Metropolitan City and governance}

It is on the agenda at the Ministry of Local Italian $^{1}$ the preparation of the law on constitutional bill already approved by the Council of Ministers of July $5,2013^{2}$, to intervene on the establishment of metropolitan cities have already started with the reform of Title V of the Constitution in 2001 and the Enabling Act of 2009.

The theme of the metropolitan city assumes a fundamental importance when analyzing the reasons for their establishment, especially in a context such as Italian, always harnessed into a rigid bureaucracy and unable to keep pace with the evolution that characterizes sudden the economy and the processes of transformation in the global scope.

These socio-economic phenomena have always been closely related to the historical evolution of urban settlements that, the configuration consists of a traditional town center with high population density and a low density around farmer, has changed in the modern townscape, widespread, which is based on the territory seamlessly between downtown, the suburbs, communities and housing conurbated concentrations productive and connected neighboring [1]. It is a new conception of the city, which has lost any form of relationship with the idea of physical territorial demarcation, to accommodate a new concept instead of an open city consistent with the dynamics of the economic flows and information and with the contamination cultural. Consequently, the traditional administrative organization has proved inadequate favoring the definition of a new model of governance of urban areas, able to administer the complexity [2].

In fact, while the first model city the institutional framework of the municipality and the province seemed appropriate to the administrative needs of the territory, which required to govern the social, economic and urban clearly distinct and quite independent of each other, in the model of "diffused city" instead the intense concentration of productive activities, the high population density, the interdependence of population centers that make up and characterize the metropolitan areas require a different institutional structure that, on the one hand, with tools and infrastructure suitable to govern the phenomena of mobility, economic development and transformations in the regime of synergistic and integrated and, on the other, provided with adequate representation of all communities affected by the needs of the metropolitan government [3].

\footnotetext{
${ }^{1}$ Just this week the Italian politics is witnessing a transition phase with the transition from Letta's government to Renzi's government which could change the schedule of activities.

2 The DL approved by the Council of Ministers establishes the abolition of the provinces. Information on http://www.Ilsole24ore.com
} 
Even before the issue of the representativeness of government, the metropolitan reality of Reggio Calabria, and the Area of the Strait of Messina in general, leads first of all to reflect on mobility and the general system of transport infrastructure understood as strategic structures designed to promote the integration of cross-strait relations and, therefore, the liveliness of the flows and their economic growth.

\section{The conurbation of the Strait Area.}

The recent establishment of Reggio Calabria as "Metropolitan City" of the Italian State ${ }^{3}$, is a historical fact of unquestionable strategic importance for the development not only of the same city of Reggio but for the entire metropolitan area of the Strait. It is in fact a concrete action that, in addition to making a reality of the capital Reggio institutional, metropolitan rank, legally recognized, introduces to the possible reconfiguration legal in the near future, the entire metropolitan area of the Strait.

The recognition of the Metropolitan Area of the Strait would be the formal act of a reality that has always existed. Despite some apparent contradictions in the evidence of episodic and rivalry, the city of Reggio and Messina are, in fact, built its history on common footprints. Placed in a central position with respect to the traffic of three continents, the two sides have always faced around the same arm of the sea, obligatory point of passage for the peoples of the Mediterranean from the remotest antiquity followed the trade routes from the East Tyrrhenian Sea. A common history, their, tied to the movement, trafficking and the phenomenon of commuting between the two sides that began in 1899 , the first public service navigation can also be transhipped railway wagons.

This event conducted in the time to affirm the idea of a real conurbation Strait involving, along with Reggio and Messina, the city of Villa San Giovanni. It was a conurbation entirely spontaneous at all guided by the instruments of urban planning and that was due, however, to the natural inclination that this assumed as ring joint physical flows of traffic. Flows of people and goods which, although limited to the city of Reggio and Messina, recorded large size also with reference to territorial largest sub-provincial, regional and national.

The local context of the Area of the Strait is characterized by great potential but at the same time reflects the infrastructure gap accumulated over the decades. In this situation, the presence of a solid governance structure of the territory, aimed at the exploitation of scarce and patchy resources in place for articulation with the processes of collective growth, constitutes the necessary basis for imparting development throughout the area. In this sense, the integrated planning and coordinate transformations, aimed at bringing together all the resources of both cities (Reggio and Messina) to build a shared program that pursues common objectives, it is without a doubt the best tool to achieve these goals. Only through the enhancement and mutually reinforcing development of existing infrastructure that aims to internalize the costs of investment and to increase the range of supply of high quality and affordable, it is possible to think that the future Metropolitan City of the Straits could become a center of attractiveness and, therefore, competitive [4].

\section{The strategic infrastructure for the integration of the two coasts of the Strait.}

The integrated planning of the two coasts prelude, as has been said, to the need for legal recognition of the Metropolitan City of the Straits. However, this is not sufficient. The Strait of Messina, is a physical-geographical break that actually prevents the real integration, especially when crossing the Strait results in high costs and time.

The constitution of the Metropolitan City of the Strait leads to reconsider the vision of the city instead aggregated to conceive a single urban reality, with all that implies. This means that all the points of the new city, all services distributed across urban (recreational, cultural, commercial, etc..)

\footnotetext{
${ }^{3}$ Reggio Calabria became Metropolitan City with the Law on Fiscal Federalism in implementation of Article 119 of the Constitution, Law no. 42 of 5 May 2009, published in the Official Gazette of 6 May 2009 and entered into force on 21 May.
} 
must be equally accessible and equally enjoyed from anywhere, at times almost acceptable and cost associated with the type of instrument used. In addition, an increased supply would produce effects on local competitiveness by reducing costs and prices of consumer goods and services.

It is clear, therefore, that only a link that performs a function of urban type that infrastructure could be very strategic for the development of the Area of the Strait, a connection can really determine the physical cohesion, functional and economical of the two shores.

\section{The infrastructure "Archimedes Bridge"}

Joining Sicily to the mainland by a system of alternative connection to the navigation has been a challenge since ancient ${ }^{4}$. Only in the second half of the 900 , however, the issue has been addressed in a concrete way by Italian institutions. The international ideas competition in 1969 for the design of stable crossing the Strait of Messina saw ex-aequo winners of the six most original project ideas, including that of the single-span suspension bridge with a length of 3,000 meters Musumeci engineer.

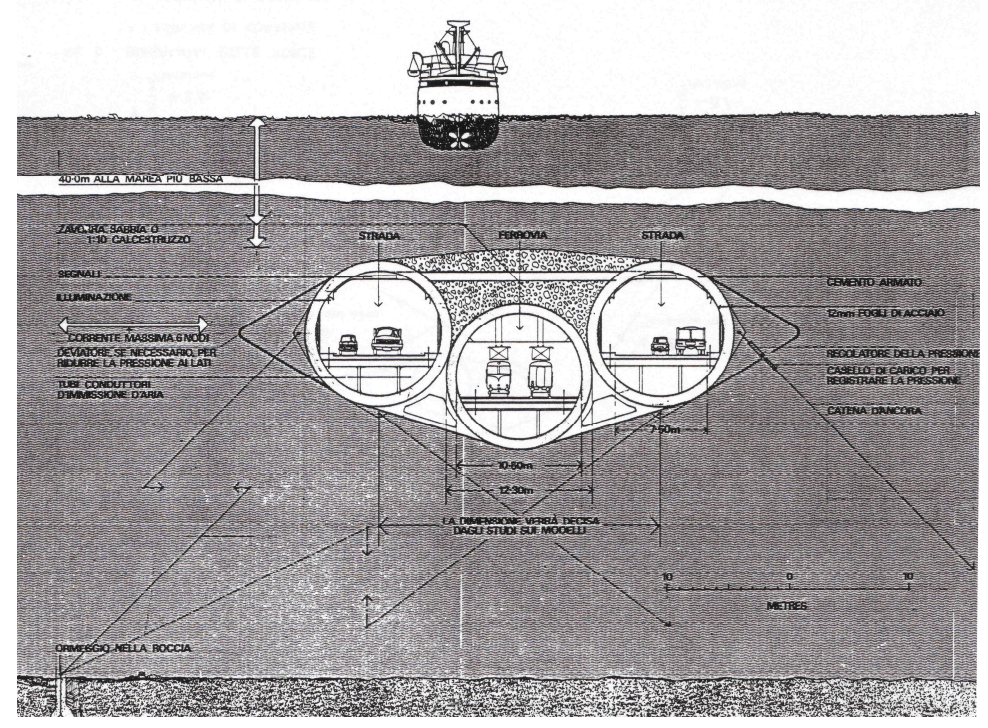

Fig. 1 - The solution proposed by Alan Grant for the crossing of the Straits of Messina

Among the winners, the idea was that most unusual proposal Englishman Alan Grant. It was a deep tunnel floating cable stayed to the seabed to counteract the hydrostatic thrust, the cross section of which is constituted by a central tube containing the railway line and two side pipes for the two directions of travel stradal. Each tube is composed of two layers of steel filled with concrete, all loaded in the upper part of loose stones for the purpose of ballast, to compensate for the upward thrust of the water. The anchoring system was provided with steel cables arranged inclined at intervals of 100-150 m (Fig. 1).

Around this operation were established two schools of researchers, was the first head of IRI, favorable crossing plane, the second ENI, an advocate of the solution of the bridge submerged. On 31 December 1992, however, was presented the design of the suspension bridge. Meanwhile, the alliance between I.R.I. and the State Railways led the Company to focus on the crossing of the Straits suspended single span [5].

Forty-five years later, the problem of crossing the Strait stable has not yet received a definitive answer from the political debate. Greater certainty comes, however, from the international scientific world, still very reticent about the possibility of making a suspension bridge with a span over two kilometers long, while expressing doubts about many less technical feasibility of a tunnel in the river bed. The prof. Federico M. Mazzolani, in fact, the President of the Governing Council of the

\footnotetext{
${ }^{4}$ The first attempt to connect the two sides of the Strait is told by Pliny the Elder in $251 \mathrm{BC}$, according to which the building, commissioned by the consul Caecilius Metellus, allowed the Romans to channel troops on a bridge of boats and barrels and tranship 140 elephants captured from Sicily to the Carthaginians.

${ }^{5}$ The longest bridge built to date is the Akashi Kaikyo Bridge in Japan, which, in its most difficult stretch is only the road bridge and covers a span of $1990 \mathrm{~m}$ with a slenderness of only ah / $\mathrm{L}=1 / 150$. The bridge designed to cross the Strait of Messina would measure 3,200 feet long with a slenderness equal to $1 / 1320 \mathrm{~m}$, and also provides rail transport.
} 
SIJLAB (acronym of Sino - Italian Joint Laboratory of Archimedes Bridge), a body of research project supported by the Ministry of Foreign Affairs, in collaboration with the Department of Structural Engineering, University "Federico II" University of Naples, at the Milan Polytechnic and the Institute of Mechanics of the Academy of Sciences of the Republic of China, concluded since 2004, the design phase of the first "submersed floating bridge" (submerged floating bridge) to connect the coast south of Shanghai with an island of Zhoushan through the Strait of Jintang.

\section{Suspension Bridge and the bridge of Archimedes in comparison}

Beyond the technical aspects, both require design solutions to address the problem of stable connections of crossing the existing road and railway infrastructures. As already stated Franco Karrer in 1973 at the conference on "Transport and the effects induced in the metropolitan area of the Strait of Messina," the construction of the infrastructure of the connection between Sicily and the continent has meant especially if it is functional to the "reduction time and therefore the cost of transport of people and goods ".

If you compare the two solutions of the suspension bridge and the bridge in the river bed, reducing lead times in the case of hemispheric relations, that is, between the island and the north of Italy, is negligible and there would be no positive effect significant both for the transport of persons and for freight6. On the contrary, this will cause a considerable increase in costs, in the case of the suspension bridge, due to the construction of the new railway line, which should be largely thought to reach a height of 70 meters above sea level bridge graft. The case is different for commuter transport for which the differences begin to be substantial. In fact, if we look at the suspension bridge road links have a total length of $12 \mathrm{~km}$, of which 7 in the gallery while the distance between the two centers of Reggio Calabria and Messina 40 miles. This means take about 30 minutes to reach the centers of the two cities, more than we currently employ fast ships (about 20 minutes). It is excluded from any consideration that the railroad could not perform the functions of urban underground.

As regards, however, the bridge of Archimedes, the link road would be reduced to $22 \mathrm{~km}$ between Reggio and Messina, and would rise from 30 to $16 \mathrm{~km}$ between Messina and Villa San Giovanni. Travel times, practically, would be halved. Also, another significant aspect is related to the railway line which, in this case, would play the function also of urban connection, over which the extra-urban, accommodating the subway cars which would greatly reduce the throughput time for commuters and would have implications positive impact on the flow of urban traffic caused by cars in cities.

\section{References}

[1] G. Nuvolati, F. Piselli (a cura di): La città: bisogni, desideri, diritti: la città diffusa: stili di vita e popolazioni metropolitane, Franco Angeli, Milano (2009)

[2] F. Patroni Griffi: Napoli Città metropolitana: ambito ottimale, governance, percorso istitutivo. Convegno organizzato dall'Unione Industriali di Napoli (Napoli, 14 gennaio 2013) (2013)

[3] G. Soricelli: Politiche pubbliche e complessità sociali. Il fenomeno delle aree metropolitane tra riassetto dell'amministrazione locale e riforme costituzionali. In Istituzioni del federalismo, fasc. 5 (2002) pp. 843 ss.

\footnotetext{
${ }^{6}$ Currently the existing rail system allows you to connect Turin and Palermo in no less than 17 and a half hours to travel the same route while on the highway it takes at least 16 hours in low traffic conditions and with a minimum number of construction sites. The realization of crossing would only allow a stable net savings of about an hour and a half to half an hour for the train and the wheel.
} 
[4] F. Calabrò, L. Della Spina: The cultural and environmental resources for sustainable development of rural areas in economically disadvantaged contexts. Economic-appraisals issues of a model of management for the valorisation of public assets. In 3rd International Conference on Energy, Environment and Sustainable Development (ICEESD 2013). Advanced Materials Research Vols. 869-870 (2014), pp 43-48

[5] V. Bettini, M. Guerzoni, A. Ziparo: Il ponte Insostenibile, Alinea editrice, Firenze (2002)

[6] F. Calabrò, L. Della Spina: The public-private partnerships in buildings regeneration: a model appraisal of the benefits and for land value capture. In: 5nd KKU International Engineering Conference 2014 (KKU-IENC 2014). ADVANCED MATERIALS RESEARCH, Vols. 931932 (2014) pp 555-559 (C) (2014) Trans Tech Publications, Switzerland doi:10.4028/www.scientific.net/AMR.931-932.555, (2014) 